\title{
Avaliação dos Equipamentos e Serviços Turísticos do Jardim Botânico, Curitiba, Paraná, (Brasil)
}

\author{
Equipment and Tourist Services Evaluation at Botanical Garden, Curitiba, Paraná, \\ (Brazil)
}

\section{Evaluación de los Equipos y Servicios Turísticos del Jardín Botánico, Curitiba, Paraná (Brasil)}

Raquel Ribeiro de Souza Silva ${ }^{1}$

\section{Resumo}

O Jardim Botânico é um dos atrativos mais visitados da cidade de Curitiba-PR e a avaliação de seus equipamentos e serviços turísticos por aqueles que o utilizam é de suma importância para sua manutenção. Nesta pesquisa foram feitas coletas de dados por meio da aplicação de questionário in loco, e foi diagnosticada a percepção dos usuários em relação à infraestrutura receptiva presente na área de estudo. Os resultados encontrados apontam que no geral o usuário está satisfeito com o atrativo, entretanto há alguns pontos, por eles citados, os quais carecem de uma atenção maior por parte da gestão local, tais como ampliação da área de alimentação, da quantidade de bebedouros e de banheiros, além da necessidade de elaboração de materiais informativos sobre o atrativo, guias internos e sinalização bilíngüe. A contribuição deste trabalho é fornecer informações relevantes, aos administradores do local no sentido de manter o Jardim Botânico de Curitiba como referência de atrativo turístico da cidade.

Palavras-chaves: Jardim Botânico; Curitiba; atrativo turístico; infraestrutura; avaliação.

\begin{abstract}
The Botanical Garden is one of the most visited attractions at Curitiba - PR, and evaluation its tourist's services by those who use it are very important for its maintenance. In this study data was collected through a questionnaire in loco, and was diagnosed with the users it perception regarding the infrastructure present at the receptive field of study. The results show that in general the user is satisfied with the appeal, however there are some points, they cited, which require greater attention by the local administration, such as increasing the food area, the amount of drinking water places and bathrooms, plus the need to provide informational materials about the attractive, internal guides and bilingual signage. The contribution of this paper is to provide relevant information to local administrators to maintain the Botanical Garden of Curitiba as a reference of tourist's attraction at the city.
\end{abstract}

Keywords: Botanical Garden; Curitiba; tourist attraction; infrastructure; evaluation.

\footnotetext{
${ }^{1}$ Bacharel em Turismo pela Universidade Estadual Paulista Júlio de Mesquita Filho. Mestre em Engenharia Florestal pela Universidade Federal do Paraná. E-mail: unesp2004@yahoo.com.br.
} 


\section{Resumen}

El Jardín Botánico es una de las atracciones más visitadas de la ciudad de Curitiba-PR, así la evaluación de sus servicios turísticos por aquellos que los utilizan es muy importante para su mantenimiento. Esta investigación incluyó la recopilación de datos a través de um cuestionario in loco y fue diagnosticado la percepción de los usuários con respecto a la actual infraestructura receptiva en el sitio de estúdio. Los resultados muestran que en general, el usuário está satisfecho con la apelación, sin embargo hay algunos puntos citados que requieren mayor atención por parte de la administración local, como el aumento del área de la alimentación, la cantidad de sítios con água potable y baños, además de la necesidad de elaborar materiales informativos sobre la atraccione, guias internas y señalización bilingüe. La contribución de este trabajo es proporcionar información pertinente a los administradores del sitio para mantener el Jardín Botánico de Curitiba como referencia de atracción turística de la ciudad.

Palabras claves: Jardín Botánico; Curitiba; atracción turística; infraestructura; evaluación.

\section{Introdução}

Ao longo dos séculos a relação de dominação do homem sobre a natureza foi representada por meio da elaboração, ordenação e decoração de jardins, os quais simbolizavam uma natureza domesticada (McHARG, 2000).

Atualmente, os jardins botânicos, dentre outras áreas verdes, desempenham um papel similar ao que representava na antiguidade, entretanto, hoje a criação destes espaços é pautada em outras justificativas, como exemplo, a preservação ambiental, áreas de lazer e recreação, e até mesmo atrações turísticas urbanas.

Os jardins botânicos são espaços diferenciados, capazes de sensibilizar os homens e despertar seu reencantamento pela natureza (PEREIRA e COSTA, 2010). Presentes no Brasil desde o período colonial, estes espaços, atualmente, vem ganhando notoriedade como atrativos turísticos.

Pearce (1991) define atrativo turístico como sendo a nomenclatura para um local, seja natural ou antropizado, cujo foco está no visitante e a atenção voltada à sua gestão. O conceito de Beni (2004, p. 302) para atrativo turístico é mais abrangente, pois inclui "todo lugar, objeto ou acontecimento que motiva o deslocamento de grupos humanos para conhecê-los". 
Diante da abundante oferta de atrativos, há um esforço no sentido de categorizá-los. Cooper et al. (2001), classifica os atrativos levando em consideração a sua localização física, seu grau de naturalidade ou artificialidade e a política de preço adotada para o acesso.

Leask (2010), por sua vez, divide os atrativos turísticos em parques temáticos e de diversão; museus e galerias; ambientes naturais: jardins, florestas e parques nacionais; locais religiosos; e patrimônio: castelos, fortes, monumentos culturais, históricos e arqueológicos, dentre outros. Beni (2004) considera todas as categorias citadas e inclui os eventos na lista de categorização dos atrativos turísticos.

Independente de sua categorização, os atrativos representam a razão de ser do turismo e possuem a capacidade de movimentar todo o sistema turístico, incentivando a demanda pela viagem na região emissora, são também importantes espaços destinados às atividades de lazer, atendendo, portanto não apenas visitantes e turistas, mas também à população local.

Segundo Dumazedier (2000, p. 34), "lazer é um conjunto de ocupações às quais o indivíduo pode entregar-se de livre vontade [...], após livrar-se ou desembaraçar-se das obrigações profissionais, familiares e sociais". Enquanto que, o termo turismo é definido pela Organização Mundial do Turismo como sendo "as atividades das pessoas que viajam e permanecem em lugares fora de seu ambiente habitual por não mais de um ano consecutivo para lazer, negócios ou outros objetivos" (OMT, 2003 p.18).

Observa-se, portanto, que lazer e turismo, embora distintos, segundo as conceituações teóricas, são atividades que se complementam e os jardins botânicos atuais constituem-se palcos onde se desenvolvem ambas as atividades. Neste contexto, a questão da qualidade torna-se um imperativo (COOPER, et al., 2001).

Para isso, os atrativos contam, portanto, com equipamentos turísticos e serviços que visam atender satisfatoriamente a demanda que os utilizam, tais como os meios de hospedagem, estabelecimentos de alimentação, de entretenimento e outros serviços (BOULLÓN, 2002).

Tratando-se dos serviços, o termo qualidade pode ser definido como a totalidade das relações entre os prestadores de serviços e as características do produto, relacionada ao ato de proporcionar satisfação ao consumidor (COOPER, et al., 2001). 
A qualidade nos serviços oferecidos e a experiência tida pelo indivíduo em sua visita aos atrativos, ainda não é uma realidade mensurável quantitativamente, e sim, segundo Swarbrooke e Horner (2002), uma “percepção nas mentes do consumidor”.

Segundo Leask (2010), em relação aos atrativos turísticos, o objetivo comum, ainda, é enfatizar o número de visitantes em detrimento da percepção que estes têm do ambiente visitado, procedimento este que inviabiliza a mensuração da qualidade dos serviços turísticos.

Frente à relevância da experiência de serviços intangíveis, a gestão dos atrativos turísticos deve possuir um foco especial no público que o utiliza, e atenção às questões administrativas e de marketing, dentro deste contexto, Leask (2010) aponta duas importantes ferramentas a serem utilizadas por gestores de atrativos turísticos: coletar dados e monitorar o comportamento do público que utiliza estes espaços.

Pearce (1991), também aponta alguns fatores a serem considerados nos atrativos turísticos: proporcionar a compreensão do público sobre o atrativo, para que desta forma, o indivíduo se identifique com o local e tenha atitudes que considerem a sua conservação; promoção de atividades que sejam responsáveis, acessíveis e estimulem a imaginação; oferecer serviços de apoio: banheiro, lojas, estacionamento, etc.

Ao se considerar os jardins botânicos como áreas de lazer e atrativos turísticos, todos os itens citados devem fazer parte da gestão destes espaços, e além destes, de acordo com a afirmação de Shackleton, et al. (2010), faz necessária a realização de pesquisas no sentido de conhecer o perfil, as motivações e o nível de satisfação dos usuários com os equipamentos e serviços disponíveis, tendo em vista a escassez de dados sobre estes tópicos nos jardins botânicos espalhados pelo mundo.

Na Cidade de Curitiba, segundo dados da Secretaria de Estado do Turismo, no ano de 2007, o Jardim Botânico de Curitiba posicionou-se em primeiro lugar no ranking dos atrativos mais visitados (INSTITUTO DE PESQUISA E PLANEJAMENTO DE CURITIBA, 2007). No ano de 2009, segundo dados do Instituto Municipal de Turismo de Curitiba, o Jardim Botânico manteve-se em primeiro lugar no ranking dos atrativos mais visitados (CURITIBA, 2009).

Considerando a relevância destes dados para o turismo, bem como para o lazer na Cidade de Curitiba, esta pesquisa tem como objetivo analisar os equipamentos e serviços turísticos do 
Jardim Botânico Municipal, e saber se a demanda que o utiliza está ou não satisfeita com a infraestrutura receptiva disponível no atrativo.

\section{Material e Métodos}

\subsection{Caracterização da área de estudo}

O objeto de estudo, Jardim Botânico Municipal, localiza-se na cidade de Curitiba, capital do Estado do Paraná, no bairro Jardim Botânico, entre a Avenida Lothário Meissner e a Rua Ostoja Roguski, conforme ilustra a figura 1. O atrativo dispõe de uma área de 17,8 ha (REDE BRASILEIRA DE JARDINS BOTÂNICOS, 2004).

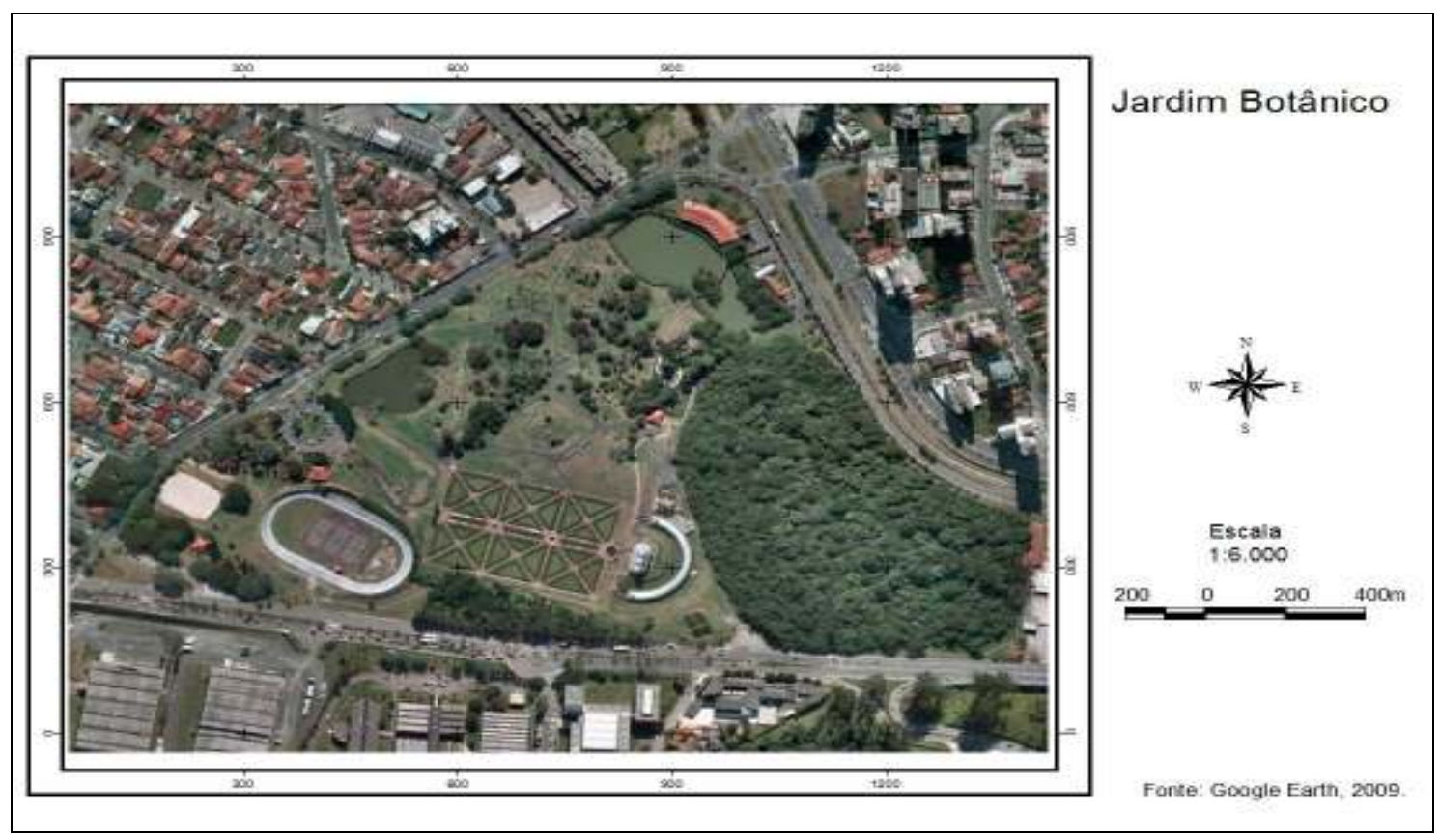

Figura 1 - Localização do Jardim Botânico Municipal de Curitiba Fonte: Google Earth (2009).

\subsection{Histórico do Jardim Botânico de Curitiba}

Inaugurado em cinco de outubro de 1991, o Jardim Botânico de Curitiba, cuja nomenclatura oficial é uma homenagem à urbanista Francisca Maria Garfunkel Rischbieter, pioneira no trabalho de planejamento urbano da capital paranaense, funciona como centro de pesquisas da 
flora do Estado do Paraná, contribui com a preservação e conservação da natureza, por meio de atividades desenvolvidas no Centro de Educação Ambiental e no Jardim das Sensações e, além disso, é considerado um dos ícones turísticos da Cidade de Curitiba (INSTITUTO DE PESQUISA E PLANEJAMENTO DE CURITIBA, 2007).

\subsection{Procedimentos metodológicos}

No sistema turístico a demanda é algo fundamental (COOPER, et al. 2001), com base neste princípio, os procedimentos metodológicos utilizados para a elaboração deste artigo foram a caracterização do usuário, a análise, a quantificação e a avaliação dos equipamentos e serviços turísticos e coleta de sugestões para a melhoria do Jardim Botânico.

\subsection{Caracterização do usuário do Jardim Botânico de Curitiba}

O procedimento de coletar dados referentes ao perfil do entrevistado é realizado com freqüência em pesquisas voltadas ao planejamento turístico (BENI, 2004), e esta coleta de dados pode ser realizada in loco, por meio de entrevistas pessoais e aplicação de questionários ou até mesmo por meio de levantamento de dados na internet utilizando-se principalmente os sites institucionais (COOPER, et al., 2001).

Estudos demonstram ainda que aspectos socioeconômicos, culturais, educacionais, demográficos, entre outros, contribuem de maneira significativa nos resultados finais de pesquisas científicas (TVEIT, 2009).

O público que utiliza o local em estudo, conforme observado em campo é diverso, há aqueles que residem no entorno do Jardim Botânico, há aqueles que o utilizam apenas como meio de passagem de uma avenida a outra, há também aqueles que trabalham no entorno e o utilizam como área de descanso em horário de almoço, desta forma, neste trabalho optou-se por caracterizar os participantes da pesquisa de usuários por ser um termo amplo, considerando que os termos visitantes e turistas, não seriam aplicáveis a todos os participantes.

O perfil do usuário do Jardim Botânico de Curitiba foi traçado com base na coleta de dados in loco por meio de aplicação de questionário (APÊNDICE 1) composto por perguntas relacionadas à idade, ao gênero, ao nível de escolaridade, e a região geográfica de procedência dos usuários. 
Foram aplicados 466 questionários entre os meses de maio e agosto de 2011. A compilação e tabulação dos dados coletados foram realizadas no programa Windows Excel 97-2003.

\subsection{Avaliação dos equipamentos e serviços turísticos do Jardim Botânico de Curitiba}

Antes de iniciar a coleta de dados por meio de questionários foi necessário solicitar uma autorização ao órgão público que administra a área de estudo, a Secretaria Municipal de Meio Ambiente de Curitiba, a qual expediu uma autorização para a realização da presente pesquisa.

Assim, a avaliação do atrativo turístico em estudo foi realizada por meio de visitas in loco, junto à aplicação de questionário aos usuários do Jardim Botânico.

\section{Resultados e Discussão}

Nas normativas de criação e funcionamento de Jardins Botânicos, estabelecidas em resoluções especificas (BRASIL, 2000) e (BRASIL, 2001), em relação aos equipamentos e serviços de apoio ao usuário consta apenas a necessidade de possuir infraestrutura suficiente para atender aos visitantes, sem maiores detalhes sobre o que seria ideal em termos quantitativos e qualitativos.

No Jardim Botânico de Curitiba foram encontrados os equipamentos e serviços descritos na tabela 1 e a partir da prévia observação do entorno da área de estudo, foi solicitado aos entrevistados que expressassem sua opinião indicando se os equipamentos e serviços mencionados no questionário eram suficientes ou não para o atendimento da demanda que os utiliza. Observou-se, entretanto, uma ausência de percepção em um número expressivo de usuários em relação aos itens abordados no questionário, por esta razão houve a necessidade de inserir junto às opções (sim) e (não) a opção (não observou).

Tabela 1 - Equipamentos e Serviços Turísticos do Jardim Botânico de Curitiba

\begin{tabular}{l|c}
\hline \multicolumn{1}{c|}{ Elementos observados } & Quantidade \\
\hline Sinalização & 43 \\
\hline Estacionamento & 1 \\
\hline Área de alimentação & 1 \\
\hline Área de educação ambiental & 1 \\
\hline Área de exercícios físicos & 2 \\
\hline Banheiros & 2 \\
\hline Lixeiras & 39 \\
\hline
\end{tabular}




\begin{tabular}{l|c}
\hline Informações turísticas & 0 \\
\hline Venda de suvenires & 1 \\
\hline Bancos para sentar & 37 \\
\hline
\end{tabular}

Fonte: elaborado pela autora.

Cabe ressaltar, portanto, que além dos objetivos de cunho ambiental, o Jardim Botânico de Curitiba também é um espaço de lazer e turismo o qual possui uma infraestrutura receptiva composta por equipamentos e serviços (Tabela 1), que são utilizados tanto pelos visitantes como pela população local.

\subsection{Características do usuário Jardim Botânico de Curitiba}

Os resultados obtidos por meio da aplicação e posterior análise dos questionários aplicados na área de estudo, descritos na tabela 2, demonstraram o perfil do usuário e a percepção dos mesmos em relação aos equipamentos e serviços turísticos disponíveis no Jardim Botânico de Curitiba.

Tabela 2 - Perfil do Usuário do Jardim Botânico de Curitiba

\begin{tabular}{llr}
\hline Gênero & Masculino & 265 \\
& Feminino & 201 \\
\hline Faixa etária & Até 18 anos & 52 \\
& De 19 a 30 anos & 178 \\
& De 31 a 45 anos & 124 \\
& De 46 a 60 anos & 79 \\
& Acima de 60 & 33 \\
\hline Escolaridade & Ensino fundamental & 51 \\
& Ensino médio & 156 \\
& Graduação & 142 \\
& Pós graduação & 117 \\
\hline
\end{tabular}

Fonte: Elaborado pela autora.

Do total de 466 entrevistados desta pesquisa 304 eram mulheres e 162 homens. A faixa etária predominante com 178 das respostas foi a de 19 a 30 anos e o grau de escolaridade mais representativo foi o ensino médio, com 156 seguido da graduação com 142 das respostas obtidas.

A tabela 3 ilustra dados referentes ao deslocamento do usuário do Jardim Botânico de Curitiba, de onde procedem, o tempo de permanência na Cidade e as motivações para realização da viagem. 
Tabela 3 - Usuário: origem, permanência e motivação

\begin{tabular}{l|l|r}
\hline Origem & Curitiba (CTBA) & 159 \\
\hline & Região metropolitana de CTBA & 27 \\
\hline & Outra cidade do Paraná & 35 \\
\hline & Outro estado & 219 \\
\hline Permanência & Outro país & 26 \\
\hline & 1 dia & 52 \\
\hline & De 2 a 5 dias & 159 \\
\hline & Mais de 5 dias & 69 \\
\hline Motivação & Residentes & 186 \\
\hline & Lazer & 159 \\
\hline & Turismo & 212 \\
\hline & Pesquisa & 8 \\
\hline & Outros & 87 \\
\hline
\end{tabular}

Fonte: Elaborado pela autora.

Identificou-se que na origem do usuário do atrativo em estudo destacam-se o residente da Cidade de Curitiba, e os residentes de outros estados, os quais representaram 159 e 219 das respostas, respectivamente.

Quanto à permanência na Cidade, a média encontrada entre o usuário do Jardim Botânico de Curitiba, foi de 2 a 5 dias, conforme demonstram as 159 respostas obtidas. Consideraram-se nesta questão, também, os usuários que permanecem por 1 dia e aqueles que afirmaram residir na Cidade, sendo 52 e 186 respectivamente as respostas afirmativas para estes itens.

Os resultados relacionados com a origem e permanência do usuário do Jardim Botânico de Curitiba encontrados nesta pesquisa coincidem com os resultados apresentados no relatório de demanda turística elaborado pelo Instituto Municipal de Turismo local (CURITIBA, 2009) e com pesquisas acadêmicas, com o tema turismo em áreas verdes de Curitiba, desenvolvidas por Kaick et al. (2006), e Ribeiro e Silveira (2006), que também afirmam ser de 2 e 5 dias a permanência média do usuário do Jardim Botânico de Curitiba, na Cidade de Curitiba.

No quesito motivação para visitar o atrativo, destacaram-se o turismo e o lazer com 212 e 159 das respostas respectivamente. Este resultado concorda com a afirmação de Andrade (2006), segundo o qual, a necessidade que os indivíduos possuem de troca de ambiente físico e de evasão é uma das motivações que impulsionam as pessoas à prática do turismo e do lazer.

Conforme observado nas respostas obtidas junto aos moradores da Cidade de Curitiba, o lazer é o principal motivo da visita ao Jardim Botânico de Curitiba, resultado que coincide com o 
estudo realizado por Hildebrand et al. (2002) no Bosque Alemão de Curitiba, no qual os entrevistados apontaram as áreas verdes como os principais locais escolhidos para a prática de lazer aos finais de semana.

\subsection{Avaliação dos equipamentos no Jardim Botânico de Curitiba}

Os equipamentos presentes no atrativo em estudo, os quais são utilizados para fins turísticos, considerados para análise e avaliação desta pesquisa foram: área de exercícios físicos; bancos; sinalização; bebedouros e lixeiras.

A tabela 4 expressa a avaliação, concedida pelos 466 entrevistados que participaram desta pesquisa, em relação à adequação dos equipamentos turísticos ao usuário do Jardim Botânico de Curitiba.

Tabela 4 - Avaliação quanto à Adequação dos Equipamentos Turísticos do Jardim Botânico de Curitiba aos seus Usuários

\begin{tabular}{lccc}
\hline Equipamentos turísticos & Sim & Não & Não observou \\
\hline Área de exercícios físicos & 310 & 35 & 121 \\
Bancos & 257 & 142 & 67 \\
Sinalização & 331 & 77 & 58 \\
Bebedouros & 81 & 277 & 108 \\
Lixeiras & 352 & 69 & 45 \\
\hline
\end{tabular}

Fonte: Elaborado pela autora.

a) Área de exercícios físicos

Este equipamento foi avaliado de maneira positiva por 310 entrevistados, enquanto que apenas 35 destes afirmaram não estarem satisfeitos e 121 não observaram o equipamento em avaliação.

Os resultados encontrados demonstram a importância deste espaço para práticas de exercícios físicos, conforme já diagnosticado em estudos conduzidos por Torrens e Santos (2003), Zannin e Szeremetta (2003), Silva et al. (2003) no Jardim Botânico de Curitiba, e embora estes autores tenham, erroneamente, o denominado como parque, seus resultados confirmam que a presença deste espaço no atrativo em estudo constitui-se em uma ponte entre turismo, lazer e bem estar para os usuários.

b) Bancos 
Neste quesito 257 entrevistados se mostraram satisfeitos com a quantidade de bancos existentes no atrativo, enquanto que 67 não observaram este equipamento e a justificativa encontrada para esse número é a localização centralizada dos bancos, os quais estão em sua maioria em volta do jardim francês e em frente à estufa. Os não satisfeitos totalizaram 142 .

De acordo com Pearce (2001) e Ignarra (2003), no planejamento e na gestão de atrativos turísticos, há de se providenciar serviços e equipamentos de apoio aos diversos tipos de usuários.

No caso do Jardim Botânico de Curitiba, a quantidade e distribuição dos bancos pode ser considerado sim um equipamento de apoio, o qual deve ser observado pela gestão, pois conforme observado em campo há uma demanda de usuários que possuem limitações físicas e por esta razão não conseguem caminhar longas distâncias sem descansar por alguns minutos.

\section{c) Sinalização}

Ao questionar sobre este equipamento ressaltou-se que se tratava na sinalização interna do Jardim Botânico de Curitiba e não da externa. Em campo observou-se que em alguns pontos a indicação presentes nas placas é confusa, fato comprovado por 77 entrevistados que afirmaram a insuficiência da quantidade e qualidade das placas indicativas. Poucos foram aqueles que não observaram este equipamento, 58, e 331 afirmaram estarem satisfeitos.

A importância de uma boa sinalização é uma prioridade e constitui-se uma deficiência em alguns jardins botânicos, conforme diagnosticado por Reis e Neto (2007) junto aos usuários do Jardim Botânico Adolpho Ducke, localizado na Cidade de Manaus e por Oliveira (2007), Oliveira e Nishida (2011) em estudo conduzido junto aos usuários do Jardim Botânico Benjamim Maranhão, localizado na Cidade de João Pessoa.

Apesar de não ser uma deficiência do Jardim Botânico de Curitiba, o quesito sinalização poderia receber melhorias e adequações. Considerando o destaque do atrativo frente aos demais existentes na Cidade de Curitiba e a presença de usuários de outras nacionalidades, a presença de placas em inglês e espanhol é um imperativo.

d) Bebedouros

Neste quesito 277 entrevistados afirmaram não estarem satisfeitos, e a justificativa observada em campo foi a localização deste equipamento e a quantidade, pois o único bebedor 
disponível encontra-se em uma área de difícil acesso para aqueles que visitam o Jardim Botânico de Curitiba pela primeira vez. Apenas 81 entrevistados mostraram-se satisfeitos e 108 não observaram a presença deste equipamento. Considerado os serviços de apoio comentados por Pearce (2001) e Ignarra (2003), a ausência de bebedouros em quantidade suficiente para atender a demanda de usuários é uma fragilidade do atrativo em estudo.

e) Lixeiras

Um número considerável de entrevistados, 352, afirmaram estar satisfeitos com a quantidade de lixeiras distribuídas na área do Jardim Botânico de Curitiba. A quantidade daqueles que não estavam satisfeitos e daqueles que não observaram, não foi expressiva, sendo 69 e 45 respectivamente.

A política ambiental relacionada à coleta e separação de lixo reciclável, praticada no município (CURITIBA, 2011), reflete-se também nos atrativos turísticos, a partir da implantação de lixeiras especificas para cada tipo de lixo, justificando assim o resultado satisfatório encontrado nas respostas relacionadas a este equipamento.

\subsection{Avaliação dos serviços no Jardim Botânico de Curitiba}

Os serviços presentes no atrativo em estudo, os quais são utilizados para fins turísticos, considerados para análise e avaliação desta pesquisa foram: área de alimentação; área de educação ambiental; banheiros; estacionamento; informação turística e loja de suvenir.

A tabela 5 expressa a avaliação, concedida pelos 466 entrevistados que participaram desta pesquisa, em relação à adequação dos serviços turísticos ao usuário do Jardim Botânico de Curitiba.

Tabela 5 - Avaliação quanto à Adequação dos Serviços Turísticos do Jardim Botânico de Curitiba aos seus Usuários

\begin{tabular}{l|r|r|r}
\hline \multicolumn{1}{c|}{ Serviços turísticos } & \multicolumn{1}{c|}{ Sim } & \multicolumn{1}{c|}{ Não } & Não observou \\
\hline Área de alimentação & 95 & 130 & 241 \\
\hline Área de educação ambiental & 254 & 43 & 169 \\
\hline Banheiros & 192 & 143 & 131 \\
\hline Estacionamento & 163 & 125 & 178 \\
\hline Informação turística & 223 & 175 & 68 \\
\hline Loja de suvenir & 187 & 68 & 211 \\
\hline Fonte: Elaborado pela autora. & & &
\end{tabular}


a) Área de alimentação

Quando questionados sobre a área de alimentação disponível dentro do Jardim Botânico de Curitiba, 241 entrevistados afirmaram não terem observado este serviço, já que não o utilizaram e 95 entrevistados afirmaram estar satisfeitos.

Entretanto, notou-se que entre as afirmações negativas e positivas quanto à satisfação com este serviço, a existência de 130 entrevistados insatisfeitos com este serviço, devido à ausência de diversidade de alimentos, os altos preços dos produtos comercializados, e o tamanho do estabelecimento.

Situações semelhantes no quesito insatisfação dos usuários com a área de alimentação foram diagnosticadas por Oliveira, (2007), Oliveira e Nishida, (2011) no Jardim Botânico Benjamim Maranhão, na Cidade de João Pessoa, Paraíba e também por Reis e Neto (2007) em estudo conduzido no Jardim Botânico Adolpho Ducke, localizado na cidade de Manaus.

O serviço de alimentação é de importância relevante em atrativos turísticos, e em alguns casos constitui-se até mesmo em elemento de identidade em localidades turísticas (MASCARENHAS e GÂNDARA, 2009). É notável, portanto, que uma avaliação positiva neste serviço também contribui para um bom desenvolvimento da atividade turística.

b) Área de educação ambiental

No quesito educação ambiental a afirmação positiva quanto à satisfação com este serviço se sobressaiu diante das demais, obtendo 254 respostas positivas. Os entrevistados mostraram-se surpresos com a diversidade de informações ambiental presentes no Museu Botânico.

Este resultado assemelha-se aos resultados de estudos realizados em outros jardins botânicos, os quais demonstraram na prática que a educação ambiental está entre os objetivos destes espaços, estejam eles localizados em âmbito nacional ou internacional (DIAS, et al, 2005), (HUGHES, et al, 2008), (SHACKLETON, et al, 2010).

Os entrevistados comentaram ainda que o Jardim Botânico de Curitiba, em sua totalidade é um espaço de educação ambiental. Ainda assim, houve 169 entrevistados não tiveram esta percepção, pois afirmaram não ter observado. Por fim, a afirmação de insatisfação com este serviço foi expressa por apenas 43 entrevistados. 
c) Banheiros

Neste quesito 192 entrevistados afirmaram estar satisfeitos, enquanto que 143 não expressaram satisfação em relação a este serviço. Segundo, Pearce (2001) e Ignarra (2003) a presença de banheiros é um dos serviços de apoio que deve ser observado pela gestão dos atrativos turísticos. Conforme observado nas respostas obtidas este item não está sendo contemplado em sua totalidade na gestão do atrativo em estudo.

Os 131 entrevistados que não observaram este serviço, segundo seus próprios comentários, foi justificada pela localização do mesmo, o qual se situa na área central do atrativo e não está facilmente visível àqueles que têm como foco de visita a estufa e o Museu Botânico.

d) Estacionamento

As respostas obtidas em relação a este serviço foram expressivas entre aqueles que consideravam suficientes e aqueles que não observaram, sendo 163 e 178, respectivamente.

Este resultado pode explicar-se devido ao fato observado no momento da coleta de dados de que muitos dos usuários não chegavam ao atrativo em carro particular e sim se utilizavam da Linha Turismo ou ônibus de excursão, enquanto outros são vizinhos do atrativo e por esta razão também não utilizam este serviço.

Neste sentido, Ribeiro e Silveira (2006), também afirmam que a Linha Turismo é o meio de acesso mais utilizado pelos indivíduos que desejam conhecer os atrativos turísticos da Cidade de Curitiba.

Os 125 entrevistados que expressaram insatisfação com o estacionamento do Jardim Botânico de Curitiba, apresentaram como justificativa o número reduzido de vagas, especialmente aos finais de semana, e a falta de segurança.

e) Informação turística

As respostas quanto ao serviço de informação turística ficaram divididas entre o sim e o não, sendo 223 e 175 respectivamente, e 68 entrevistados que não observaram o serviço em análise.

Apesar da proximidade dos resultados entre os entrevistados que afirmaram estar satisfeitos e aqueles que negaram, foi possível notar em campo que a ausência de um guia interno e de um posto de informação são fragilidades do atrativo, as quais, no contexto de serviço de apoio ao 
usuário comentado por Ignarra (2003), deveriam ser compreendidas como prioridade de ação pela gestão local.

Uma informação relevante encontrada junto às respostas dos entrevistados foi a de que alguns deles afirmaram que não se sentiram bem caso houvesse uma quantidade excessiva de informações ou de pessoas destinadas a atendê-los dentro do atrativo, pois preferiam não ter ninguém "incomodando-os" no percurso de seu passeio.

f) Loja de suvenir

A quantidade de entrevistados que não observaram este serviço se destaca frente aos demais, totalizando 211, e a justificativa, conforme observação em campo, para a ausência de percepção do usuário foi o tempo reduzido de permanência dentro do atrativo e a localização da loja de suvenir.

Os 68 entrevistados que expressaram sua insatisfação com este serviço o fizeram pela ausência de diversidade de produtos comercializados e o alto valor dos mesmos. Ainda assim, 187 entrevistados afirmaram estar satisfeitos com a loja de suvenir disponível no atrativo.

A presença de comércio dentro espaços turísticos, faz parte do conjunto de serviços públicos necessários ao ato de consumir, o qual é característico das atividades relacionadas ao turismo (IGNARRA, 2003).

Após a avaliação individual dos entrevistados quantos aos equipamentos e serviços disponíveis aos usuários do Jardim Botânico, solicitou-se uma avaliação geral, considerando a existência significativa da parcela daqueles que não observaram diversos itens, e ainda assim, afirmaram estar satisfeitos. Observou-se ao final que $73,81 \%$ dos entrevistados estavam totalmente satisfeitos e $26,19 \%$ parcialmente satisfeitos. Nenhum dos entrevistados expressou insatisfação com o atrativo, conforme demonstra a tabela 6.

Tabela 6 - Avaliação Geral, Serviços e Equipamentos JB

\begin{tabular}{l|c} 
Totalmente satisfeito & \\
\hline Quantidade & \\
Percentagem & 344 \\
\hline & $74 \%$ \\
Parcialmente satisfeito & \\
\hline Quantidade & 122 \\
Percentagem & $26 \%$ \\
\hline
\end{tabular}




\begin{tabular}{l|c}
\hline Insatisfeito & 0 \\
\hline Total & 466 \\
Total percentagem & $100 \%$ \\
\hline
\end{tabular}

Fonte: Elaborado pela autora.

\subsection{Sugestões}

Os entrevistados desta pesquisa tiveram um espaço para expressarem suas sugestões e idéias para que o atrativo pudesse ser melhorado e a visita se tornasse mais agradável e informativa. Alguns deles não tiveram nenhuma ideia ou sugestão para o atrativo enquanto que outros sugeriram mais de uma melhoria.

Notou-se que as sugestões surgiram da análise realizada por meio do questionário aplicado, pois os pontos fracos do atrativo demonstrados nos resultados figuram entre as sugestões, tais como ampliação da área de alimentação, do estacionamento, da quantidade de bebedouros, de bancos, de banheiros e de lixeiras. Foram sugeridas também a criação de um posto de informação turística, a presença de guias internos, e a distribuição de mapa e folder informativo sobre a história e os atrativos internos do Jardim Botânico de Curitiba.

\section{Conclusões}

A avaliação dos equipamentos e serviços destinados a atividade turística, do Jardim Botânico de Curitiba, realizada pelos usuários do atrativo, os quais se dispuseram a serem entrevistados para a realização desta pesquisa apontou os pontos fracos e fortes da área de estudo, considerando o contexto de infraestrutura receptiva.

Assim, observou-se que de forma geral o usuário está satisfeito com o atrativo, entretanto existem alguns itens que poderiam ser aprimorados conforme demonstraram os resultados desta pesquisa.

Na percepção do usuário participante desta pesquisa, a maior deficiência do atrativo em estudo, é a área de alimentação e o local disponível para se beber água. Conforme observado em campo, a área de alimentação não serve refeições, pratica valores altos, e não possui diversidade de produtos. Quanto ao bebedouro, há apenas um em toda a extensão do atrativo. 
Observaram-se, também resultados muito próximos de satisfação e insatisfação nos itens quantidade de banheiros e informação turística, pois há apenas um banheiro em funcionamento e nenhum posto de informações turísticas dentro do atrativo.

Em relação à quantidade expressiva de usuários que não observaram muitos dos itens abordados no questionário aplicado, a explicação plausível pode ser a brevidade da visita, observada no momento da coleta de dados, que resulta em um baixo nível de interesse do usuário pelo atrativo como um todo.

Contudo, os resultados obtidos por intermédio dos entrevistados que tiveram uma percepção mais crítica sobre o atrativo pode ser um subsídio aos administradores do local, pois de acordo com Moraes (2008), o investimento em infraestrutura pode elevar o patamar de qualidade de um atrativo, criar uma expectativa de uma nova visita e a promover a indicação do local a terceiros.

Cabe ainda ressaltar aqui que a gestão do Jardim Botânico de Curitiba, diferente dos demais jardins botânicos do país, é municipal, o que lhe confere um cuidado mais específico, há também uma parceria com o setor privado, o grupo o Boticário, e, além disso, existe uma associação denominada amigos do Jardim Botânico de Curitiba.

Conforme já destacado por Luchiari (1998), a participação dos vários segmentos da sociedade e a mobilização destes vários grupos de interesse para debater e adequar o planejamento local é o que determina a força de um lugar.

Conclui-se, portanto, que embora a satisfação geral dos usuários em relação aos equipamentos e serviços turísticos presentes no local tenham sido elevadas, os apontamentos aqui discutidos devem ser considerados para aprimorar a experiência de visitação e mantê-lo como referência de atrativo turístico da cidade de Curitiba.

\section{Referências}

ANDRADE, J. V. Turismo Fundamentos e Dimensões. 8. ed. São Paulo: Ática, 2006.

BENI, M. C. Análise estrutural do turismo. São Paulo: Editora Senac São Paulo, 2004.

BOULLÓN, R. C. Planejamento do Espaço Turístico. Bauru, SP: EDUSC, 2002.

BRASIL. Resolução Conama $n^{\circ} 266$ de 03 de agosto de 2000, estabelece diretrizes para a criação de jardins botânicos. 
BRASIL. Resolução Conama $n^{\circ} 287$ de 30 de agosto de 2001, complementa a resolução 266.

COOPER, C.; FLETCHER, J.; WANHILL, S.; GILBERT, D.; SHEPHERD, R. Turismo, Princípios e Práticas. Porto Alegre: Bookman, 2001.

CURITIBA. Prefeitura Municipal de Curitiba. Lixo. Disponível em: $<$ http://www.curitiba.pr.gov.br/servicos/cidadao/coleta-de-lixo-que-nao-e-lixo-lixo-reciclavel/530>. Acesso em: 29 ago. 2011.

CURITIBA. Instituto Municipal de Turismo. Pesquisa de demanda turística, perfil e opinião. Curitiba, 2009.

DIAS, M. et al. Espaços não-formais de ensino e o currículo de ciências. Ciência. Cult, v.57, n.4, p. 21-23, 2005.

DUMAZEDIER, J. Lazer e Cultura Popular. São Paulo: Trad. Maria L. Machado. 3. ed. São Paulo: Perspectiva, 2000.

GOOGLE EARTH. Mapa Jardim Botânico Municipal. Curitiba, 2009.

HILDEBRAND, E., et al. "Valoração Contigente" na avaliação econômica de áreas verdes urbanas. Floresta, v. 32, n. 1, p. 121-132, 2002.

HUGHES, K. et al. Environmental awareness, interests and motives of botanic gardens visitors: implications for interpretative practice. Tourism Management, v. 29, p. 439-444, 2008.

IGNARRA, L. R. Fundamentos do turismo. São Paulo: Pioneira Thomson, 2003.

INSTITUTO DE PESQUISA E PLANEJAMENTO URBANO DE CURITIBA (IPPUC). Estatística Demanda Turística de Curitiba, $2007 . \quad$ Disponível em: <http://www.ippuc.org.br/.../Curitiba_em_dados_Pesquisa.asp>. Acesso em: 31 mai. 2010.

INSTITUTO DE PESQUISA E PLANEJAMENTO URBANO DE CURITIBA (IPPUC). Histórico dos Parques e Bosques. Disponível em: <http//www.ippuc.org.br>. Acesso em: 31 mai. 2010.

KAICK, J. A. M.; HARDT, L. P.; OBA, L. T. Contribuição dos Parques Urbanos e Áreas Verdes como Atrativos Turísticos em Curitiba - Paraná. In: Encontro da ANPPAS, III, Brasília /DF, 23 26/05/2006. Disponível em: <http://www.anppas.org.br/encontro.../TA331-06032006-120013.DOC>. Acesso em: 23 nov. 2010.

LEASK, A. Progress in visitor attraction research: Towards more effective management. Tourism Management, v. 31, p. 155-166, 2010.

LUCHIARI, M. T. D. P. Urbanização turística. Um novo nexo entre o lugar e o mundo. In: LIMA, L. C. Da cidade a campo. A diversidade do saber-fazer turístico. Fortaleza: UECE, 1998, p.15-29.

MASCARENHAS, R. G. T., GÂNDARA, J. M. G. A diversidade gastronômica como elemento de identidade e atrativo turístico na região dos Campos Gerais do Paraná: um estudo de caso no município de Castro. Revista Geografar, 2009. Disponível em: $<$ http://ojs.c3sl.ufpr.br/ojs2/index.php/geografar/article/viewFile/14360/9663>. Acesso em: 20 set. 2011.

McHARG, I. L. Proyectar con la Naturaleza. Barcelona: Editorial Gustavo Gili, SA, 2000.

MORAES, A. V. Análise da Infraestrutura dos Atrativos Naturais do Município de Jardim. $60 \mathrm{f}$. Monografia (Graduação em Turismo). Universidade Estadual do Mato Grosso do Sul, Dourados, Mato Grosso do Sul, 2008.

OLIVEIRA, S. C. C. Percepção dos visitantes sobre as trilhas interpretativas do Jardim Botânico Benjamim Maranhão, João Pessoa (Paraíba, Brasil). Monografia apresentada ao Curso de Turismo da Universidade Federal da Paraíba, João Pessoa, PB, 2007. 
OLIVEIRA, S. C. C.; NISHIDA, A. K. A interpretação ambiental como instrumento de diversificação das atividades recreativas e educativas das trilhas do jardim botânico benjamim maranhão ( João Pessoa, Paraíba, Brasil). Revista Turismo Visão e Ação - Eletrônica, v. 13, n. 2, p. 166-185, 2011.

OMT, ORGANIZAÇÃO MUNDIAL DO TURISMO. Turismo internacional: uma perspectiva global. 2. ed. Porto Alegre: Bookmann, 2003.

PEARCE, P. Analysing tourist attractions. Journal of Tourism Studies, v.2, n.1, p. 46-55, 1991.

PEREIRA, T. S.; COSTA, M. L. M. N. da. Os Jardins Botânicos brasileiros: desafios e potencialidades. Ciência Cult, v. 62, n. 1, p. 23-25, 2010.

REDE BRASILEIRA DE JARDINS BOTÂNICOS (RBJB). Jardim Botânico Municipal FMGR. Diversidade biológica nos jardins botânicos brasileiros. Rio de Janeiro, 2004.

REIS, R. S.; NETO, A. R. C. Planejamento e organização do espaço das unidades de conservação de Manaus para a promoção turística. Revista Eletrônica Aboré. Escola Superior de Artes e Turismo, p. $1-11,2007$.

RIBEIRO, R. M.; SILVEIRA, M. A. T. Planejamento Urbano, Lazer e Turismo: Os Parques Públicos em Curitiba - PR. Turismo Visão e Ação, vol. 8, n.2, p. 309 - 321, 2006.

SILVA, D. A. S. et al. Barreiras e facilitadores de atividades físicas em frequentadores de parques públicos. Motriz, Rio Claro, v.15 n.2 p.219-227, 2003.

SHACKLETON, C. M., et al. The use and appreciation of botanical gardens as urban green spaces in South Africa. Urban Forestry \& Urban Greening, v. 9, p. 49-55, 2010.

SWARBROOKE, J.; HORNER, S. O comportamento do consumidor no turismo. São Paulo: Aleph, 2002.

TORRENS, L. G. S.; SANTOS, M. G. Atuação do profissional de Educação Física em parques. Revista Brasileira Ciência e Movimento, v. 11 n. 1 p. 41-44, 2003.

TVEIT, M. S. Indicators of visual scale as predictors of landscape preference: a comparison between groups. Journal of Environmental Management, v. 90, 2009, p. 2882-2888.

ZANNIN, P. H. T.; SZEREMETTA, B. Avaliação da poluição sonora no parque Jardim Botânico de Curitiba, Paraná, Brasil. Caderno Saúde Pública, v.19, n. 2, p. 683-686, Rio de Janeiro, 2003.

\section{Recebido em: 04/10/2011}

Aprovado em: 20/12/2011 (1 ${ }^{\mathrm{a}}$ versão) $06 / 03 / 2012$ (2ª versão) 
APÊNDICE 1

Questionário avaliação turismo

\author{
Universidade Federal do Paraná \\ Programa de Pós-Graduação em Engenharia Florestal
}

Local da coleta Data Dia da semana

Clima

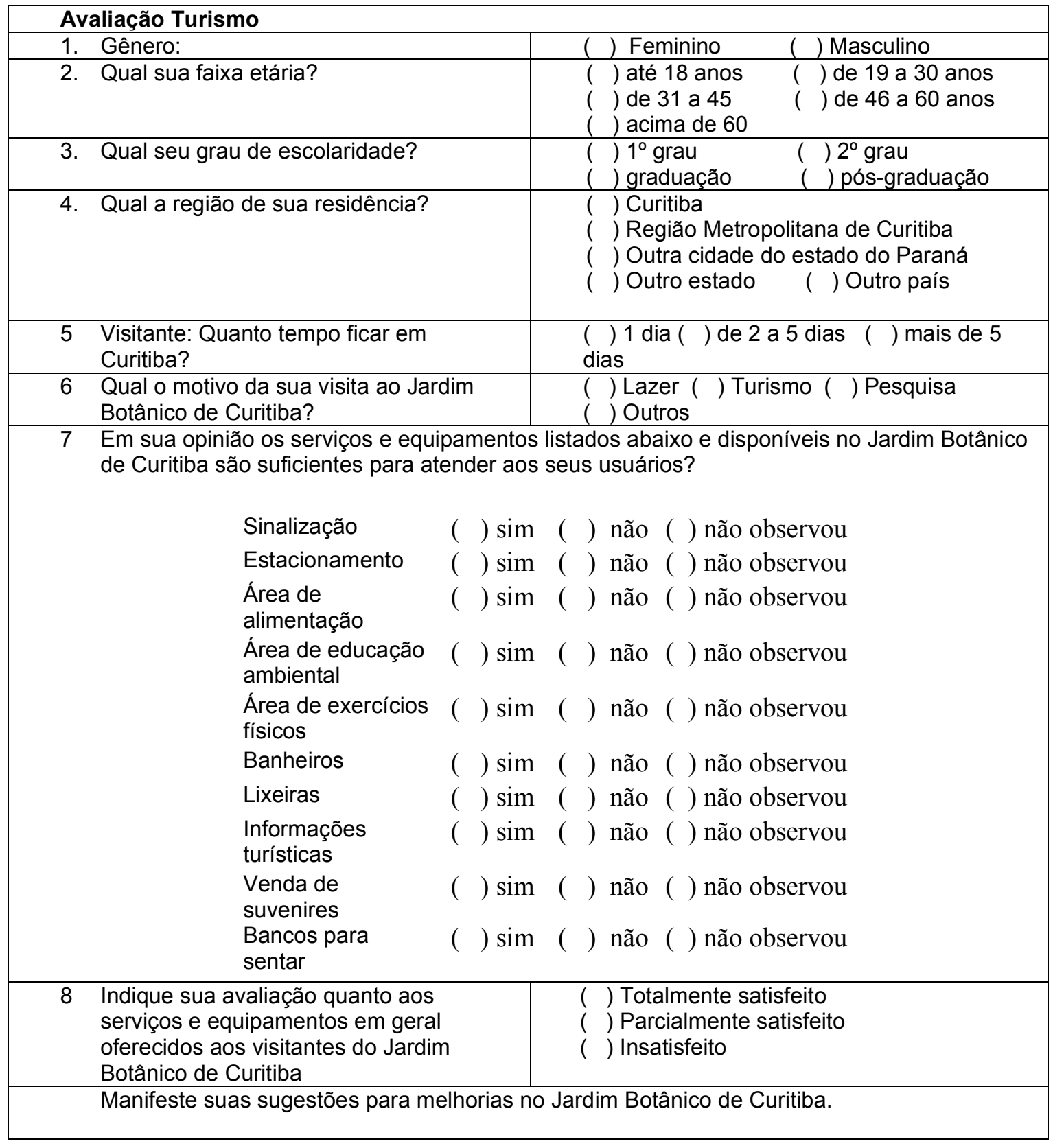

